\title{
Thinking outside the plot: monitoring forest biodiversity for social-ecological research
}

\author{
Carl F. Salk ${ }^{1}$, Robin Chazdon $^{2,3}$ and Daniel Waiswa ${ }^{4}$
}

\begin{abstract}
Protecting biodiversity, either for its own sake or for its value to humanity, is a principal goal of conservation efforts worldwide. For this reason, many studies on the social science of resource management and governance seek to quantify biodiversity outcomes. Here, we focus on the International Forestry Resources and Institutions program to demonstrate some of the challenges of quantitative biodiversity assessment and suggest ways to overcome them. One of this program's research goals is to understand the causes of biodiversity loss, which is explicitly assessed using plot-based forest sampling. Plot-based methods to capture biodiversity changes require huge amounts of data. Even if sampling is sufficient, existing protocols can only capture changes in the types of species actually sampled, typically trees. Other elements of biodiversity are not censused, including animals, herbs, shrubs, fungi, and epiphytes that may provide medicine, food, wildlife habitat, trade items, or cultural goods. Using case studies of two sites in Uganda, we demonstrate that more spatially extensive surveys targeting multiple types of data can give a broader picture of forest status and changes than can plot-based sampling alone; many relevant variables can be observed while traveling among plot points with little additional effort. Reviewing the ecological literature, we identify correlates of forest status that can supplement plot-based sampling. These include large trees, epiphyte-laden trees, culturally or commercially valuable species, large stumps, and evidence of hunting and trapping. Further, data elicited from local resource users can play an important role in biodiversity monitoring. These findings suggest that effective biodiversity monitoring may be within easier reach than previously thought, although robust comparisons among sites remains a challenge, especially when climate, soils, or site history differ greatly.
\end{abstract}

Key Words: biodiversity monitoring; community-based monitoring; conservation; participatory monitoring; socio-ecological studies

\section{INTRODUCTION}

It is widely agreed that biodiversity is important for human wellbeing and ecosystem function (Millennium Ecosystem Assessment 2005, Naeem et al. 2016). For example, forests with more tree species grow faster in a given climate (Liang et al. 2016). Diversity makes communities more resilient to pests and related disturbances (Cardinale et al. 2003, Fornoff et al. 2019) and provides many other valuable ecosystem services, from crop pollination and flood control to medicinal plants (Díaz et al. 2006, Justus et al. 2009, Mace et al. 2012). Biodiversity also has many less tangible benefits such as aesthetic appreciation of nature (Chapin et al. 2000), the value of knowing that unique organisms are found in nature (Alexander 2000), and the belief that biodiversity simply has an intrinsic right to exist (Piccolo et al. 2018). Given these benefits, it is not surprising how much public interest, policy focus, research, and money biodiversity garners. Many regions host active research into how forest conservation depends on factors as diverse as local rule-making (Persha et al. 2011), externally provided incentives (Harvey et al. 2010), and subsistence dependence on fuelwood (Naughton-Treves et al. 2007). Quantifying biodiversity status in different locations is a crucial step to understand better what institutions and conditions lead to desired results.

Many proxies are used for biodiversity assessment in different settings and scales. Some measures are of minimal relevance, for instance, the amount of money spent on conservation programs; these figures are virtually the only quantitative information presented in annual reports of the U.S. Agency for International Development biodiversity conservation programs (USAID
2015). More relevant proxies include geospatial analysis of satellite-derived forest coverage or patterns of coverage change (e.g., Ribeiro et al. 2009, Hansen et al. 2013). These measures also have limitations. Although biodiversity indisputably suffers when mature forests are destroyed, the presence of trees is incomplete evidence of biodiversity protection. Selective logging can cause long-term changes in forest composition (Baraloto et al. 2012). Overhunting leads to "empty forests", with persisting consequences, not just for the missing animal species but for plants that benefit from their pollination, seed dispersal, and regulation via herbivory (Wright et al. 2007, Terborgh et al. 2008, Effiom et al. 2013). Remote sensing offers some help in this realm. Selective logging is detectable in increasingly available high-resolution imagery (Asner et al. 2005), and certain spectral signals are correlated with the diversity of forest canopies (Carlson et al. 2007). These methods can be combined with other geospatial data to model conservation-related variables such as extinction risk and optimal reserve configurations (Ferrier and Drielsma 2010, Pearson et al. 2014). However, depleted wildlife, seedling recruitment failure, plant invasions, and species-specific phenomena are so far only detectable by remote sensing in special cases, typically large species or spatially extensive changes (Pettorelli et al. 2014). For this reason, field-based biodiversity data will continue to be important for the foreseeable future, particularly in small forest parcels and areas with heavy subsistence dependence that dominate much of the nonindustrialized world.

Field measurement of biodiversity status or change is complex and time consuming (Dornelas et al. 2013). The gold standard 
for biodiversity assessment is a mapped stand (for plants) or systematic observations or trapping surveys by skilled naturalists (for animals), ideally with repeated visits over seasons, years, or decades. Reliable estimation by most commonly used biodiversity metrics requires intensive sampling (Salk et al. 2013). Plot-based surveys are expensive and need workers skilled in sampling and identifying species. This level of data is only available for a handful of sites around the world and is almost never available in research into the societal drivers of forest outcomes, especially for comparative or statistical studies examining trends among many sites. Even when there are sufficient data, the relative usefulness of different biodiversity metrics is debated (Gotelli and Colwell 2001, Justus 2011), so well-resourced assessments in favorable circumstances may not provide useful measurements of biodiversity. Rapid assessment protocols may partially balance speed and data quality (Jones and Eggleton 2000). However, they rely on teams with specialized expertise to identify local plants, animals, or other taxa.

Because of these challenges, practical and relevant proxies for local biodiversity would benefit researchers, policy makers, and conservationists. Here, we explore some nonplot methods for local-scale biodiversity assessment using a combination of literature study and field data. We focus on case studies of two sites in Uganda that experience some degree of illegal wood extraction. The sites are assessed with plot-based composition metrics plus other forest observations and conversations with key informants. By combining quantitative analyses and informal observations, we find that nonplot methods are an efficient way of assessing the effects of harvesting on biodiversity. Further, we argue that these options need not place undue burdens on field researchers, their staff, or their budgets. Finally, we provide a list of alternative data collection schemes for biodiversity assessment derived from a literature review and our field experience. Although we focus primarily on biodiversity as an outcome variable for social science studies, many of the approaches we propose are clearly useful for other purposes, including evaluating restoration projects. These methods, implemented either as expert-driven or participatory community-based monitoring, can supplement ecological- and forestry-style plot-based sampling to build a more integrative understanding of forest change.

\section{Background on the International Forestry Resources and Institutions program}

We use the International Forestry Resources and Institutions (IFRI) program to examine the gap between the goals of research into local resource institutions' effects on biodiversity and what is actually possible to measure. The IFRI program was initiated by Elinor Ostrom in the early $1990 \mathrm{~s}$ as an international collaboration to study the management of forests as commonpool resources. All participating consortia use the same protocol to gather data on communities and their forests (Wertime 2008). This protocol assembles information on hundreds of ecological and social variables. Ecological outcomes are mostly assessed using plot-based forest inventories, and in revisited sites, these surveys can, in principle, be used to track quantitative changes in forest stocking or biodiversity. Participatory rural appraisal (PRA) methods are used to collect variables on demographics, institutions, forest products, and their interrelations. PRAs also yield useful information about forest changes, although it is not always integrated well with forest plot data.
The IFRI manual makes clear that understanding the effects of community forestry on biodiversity is a central goal of the research program: "Researchers seek an empirically based consensus about the principal causes of deforestation and loss of biodiversity" (Wertime 2008:I-4). The manual also states that biodiversity outcomes are a primary goal of forest sampling.

The purpose of the Forest Plot Form (Form P) is to
record the names, extent of cover, and sizes of plant
species within each forest. The information collected in
each plot will be aggregated to describe the forest as a
whole. Importance values of tree species based on density,
frequency, and dominance, as well as diversity indices,
may be readily calculated from these data. Biodiversity,
size class structure, and abundance of plants ranked as
priority species by local user groups may also be
calculated. (Wertime 2008:I-5).

Previous research has shown that such methods are inadequate to track changes in plant communities in even moderately diverse tropical forests (Dornelas et al. 2013), particularly when stands are spatially heterogeneous (Salk et al. 2013). Further, many biodiversity metrics are confounded by factors such as variable stem density (Gotelli and Colwell 2001) and unclear definitions (Justus 2011). Social scientists regularly seek to use IFRI plot data to generate biodiversity response variables in social-ecological studies that examine institutional or other predictors of forest management success across many sites (e.g., Persha et al. 2011). Although we are critical of the IFRI approach to biodiversity assessment, we do not see these problems as unique to IFRI. We chose this focus simply because IFRI maintains the world's largest database of community-managed forest outcomes, and we have previously used it extensively.

\section{METHODS}

\section{Case study sites}

Our study is based on PRA data collected in 2013 at the Mpanga and Nyabyeya IFRI sites in Uganda and forest plot data from those sites from the 1990s to the 2010s. The IFRI protocol gives full details of site data collection (Wertime 2008). For our purposes, the most important data were information on local livelihoods and forest condition. Livelihood data and most site information described in the following two paragraphs were collected through participatory rural appraisals and informal conversations with key stakeholders, particularly community members and forestry officials or guards.

The Mpanga site is centered on the Mpanga Central Forest Reserve $\left(0.21^{\circ} \mathrm{N}, 32.29^{\circ} \mathrm{E}\right)$, located on the Masaka highway approximately $30 \mathrm{~km}$ southwest of Kampala City. This 453-ha tropical high forest is managed by Uganda's National Forestry Authority (NFA). The site encompasses two neighboring villages whose residents rely heavily on the forest for fuelwood and to a lesser extent for hunting and collection of plants used as food and medicine. Drum making is an important source of income for men in these communities, although it relies on illegally harvested wood. The historically most sought-after tree species for drum making in this site were reported as Polyscias fulva (Araliaceae), Maesopsis eminii (Rhamnaceae), and Antiaris toxicaria (Moraceae). Wood from these trees reputedly produces good sound quality in drums. There is a ready local market for drums; 
they are sold directly to tourists in stalls along the nearby Kampala-Masaka highway. Because these drums are made from a single piece of hollowed out wood, they can only be made from large-diameter tree trunks, placing substantial pressure on the forest. The bulk of the data reported below comes from a site visit in July 2013, with additional data from visits in 2004, 2000, and 1994.

The Nyabyeya site encompasses Rwensama Central Forest Reserve $\left(1.665^{\circ} \mathrm{N}, 31.525^{\circ} \mathrm{E}\right)$, a 135 -ha tropical high forest separated by approximately $500 \mathrm{~m}$ from the much larger Budongo Central Forest Reserve. This remote site in northwestern Uganda is an approximately 1.5-h drive from Masindi, the nearest market town. As recently as the 2006 study visit, this site included another forest area that has since been entirely converted to agriculture. Rwensama Central Forest Reserve is managed by Nyabyeya Forestry College as a research and training forest on behalf of the NFA. This forest is crucial to local households for firewood and is also a source of illegally harvested timber. The key data from this site were collected during a visit in August 2013, with additional forest data from a visit in 2006

\section{Forest data collection}

Quantitative forest data were collected using the IFRI forest plot protocol (Wertime 2008), which uses circular plots with $10 \mathrm{~m}$ radius (thus covering 0.0314 ha each). Within each plot, all trees $\geq 10 \mathrm{~cm}$ diameter at breast height are measured and identified to species by expert foresters. For our study, all site visits consisted of 30 plots for a total survey area of 0.942 ha. Plots were centered on points randomly preselected from within the boundaries of the forest with the help of geographical information systems software; all locations within each forest had an equal probability of selection. Plot points were located in the field with the aid of handheld geographical positioning system devices.

Supplemental observations of the forest were made mostly while carrying out plot-based work, especially when walking between plots. Field workers noted different types of evidence of harvesting and, in some cases, documented them with photographs. Additional information on these activities came from discussions with local forest officials and community members.

\section{Analytical methods}

To illustrate the detection of forest changes, we used the IFRI forest plot data to calculate changes in basal area (BA) and species richness in the two study forests since the first site visit. Basal area was calculated in units of $\mathrm{m}^{2} /$ ha by dividing the cross-sectional area of all surveyed trees (computed as $\mathrm{BA}=\Sigma_{\mathrm{i}} \pi\left(d_{\mathrm{i}} / 2\right)^{2}$, where $d_{\mathrm{i}}$ are the diameters at breast height of each surveyed tree) by the area of a plot. Stand-level basal area values were computed by averaging across all plots from a visit. Variances among plots were used to compute $95 \%$ confidence intervals for basal area. We used a rarefaction-based method to calculate the expected number of tree species encountered in a random sample of 50 tree stems. For each site-visit combination, 10,000 samples of 50 randomly selected stems each were used to generate a distribution of expected number of species from which we computed the median and $95 \%$ confidence intervals of rarefied species richness. These distributions were also used to calculate probabilities of observing changes in species richness estimates between different site visit pairs resulting from chance. This metric was computed as the proportion of 50 stem subsamples in year 1 having more species than the corresponding sample in year 2 , and so forth for all pairs of years (see site descriptions for visit years). For the Mpanga site, we also looked at population and BA changes for the key drummaking species. Statistical differences in BA among site visits were assessed using t-tests, Mann-Whitney-Wilcoxon tests, or ANOVAs, depending on the number of visits and whether parametric assumptions were met. All analyses were implemented in $\mathrm{R}$ version 3.0.2 ( $\mathrm{R}$ Core Team 2014).

\section{RESULTS}

\section{Mpanga}

In Mpanga Forest, no clear trend was seen across the four visits for either stand BA density or species richness (Fig. 1A,B). Both attributes showed similar trends, peaking during the 2004 visit. However, all statistical tests of differences among visits fell far short of typical standards of significance for both BA (ANOVA: $\left.P=0.72, F_{1,118}=0.1291\right)$ and rarefied tree diversity (randomizations: $P>0.05$ ).

Fig. 1. Trends in measures of forest structure and biodiversity from plot-based measurements in Mpanga Central Forest Reserve near Mpigi, Uganda. Sampling effort was the same during both site visits: 30 circular plots each covering 0.0314 ha. Mean (line) and 95\% confidence intervals (grey) for basal area of all trees $\geq 10 \mathrm{~cm}$ diameter at breast height (A) and tree species richness in a 50 stem sample (B). Number of stems sampled (C) and basal area (D) of three tree species used for drum making. No statistically significant differences were found among site visits for basal area (A) or tree richness (B). No statistical tests were performed for (C) and (D) because of small sample sizes.
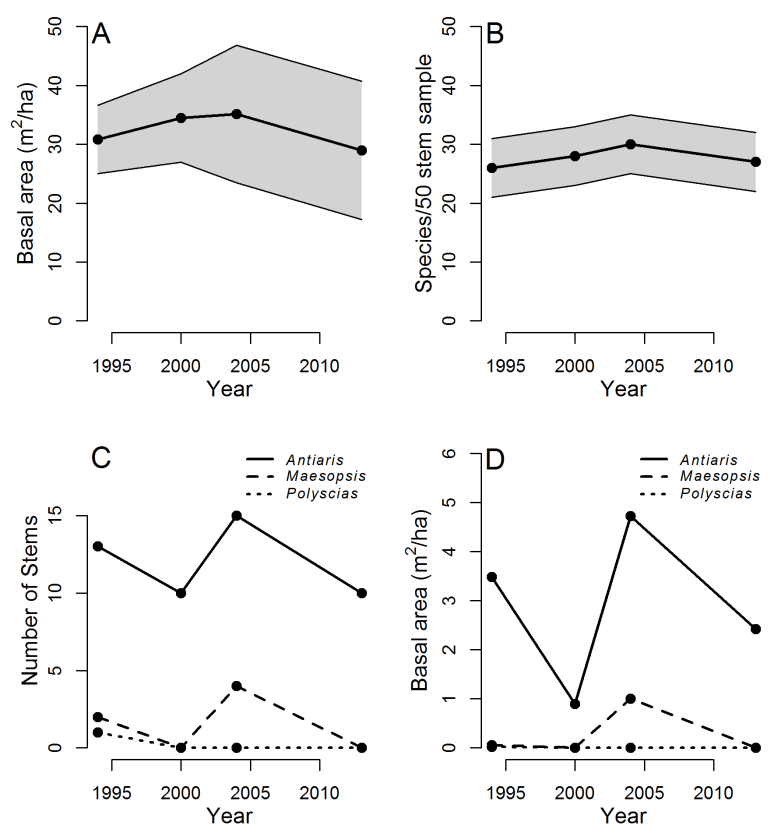
The Mpanga Forest guards reported that the preferred drummaking species have been largely eliminated from the forest, so drum makers seek whatever species they can find of sufficient size (Fig. 2A). The drums made from this wood (Fig. 2B) are sold along the nearby highway (Fig. 2C,D). Because the historical drum-making species were encountered only very rarely in forest plots, no discernible pattern, let alone a statistically significant trend, was observed (Fig. 1C,D). However, during plot fieldwork in 2013, we frequently saw large freshly cut stumps throughout the forest (Fig. 2A), consistent with ongoing harvest. By stepping down the ladder of species desirability, most drums now produced in the area are purely decorative and make little resonant sound when struck, but these are still readily purchased from roadside stalls by tourists. Local villagers have the legal right to collect fallen dead wood for domestic fuel use, but not to harvest live trees, especially large ones. However, these residents report substantial conflict between communities and the forest guards, even for legal firewood harvesting.

Fig. 2. Stages of drum making in Mpanga Central Forest Reserve near Mpigi, Uganda. (A) Felling of trees (which is contrary to forest regulations), resulting in a large stump (foreground), and a fallen log (background). Most of this tree has been cut up and chipped out to make blank drums. (B) A drum-making yard showing sectioned logs used as raw material (foreground) and drums in various stages of manufacture (background). (C) Finished drums and other handicrafts for sale in roadside stalls. (D) Close-up view of finished drums.

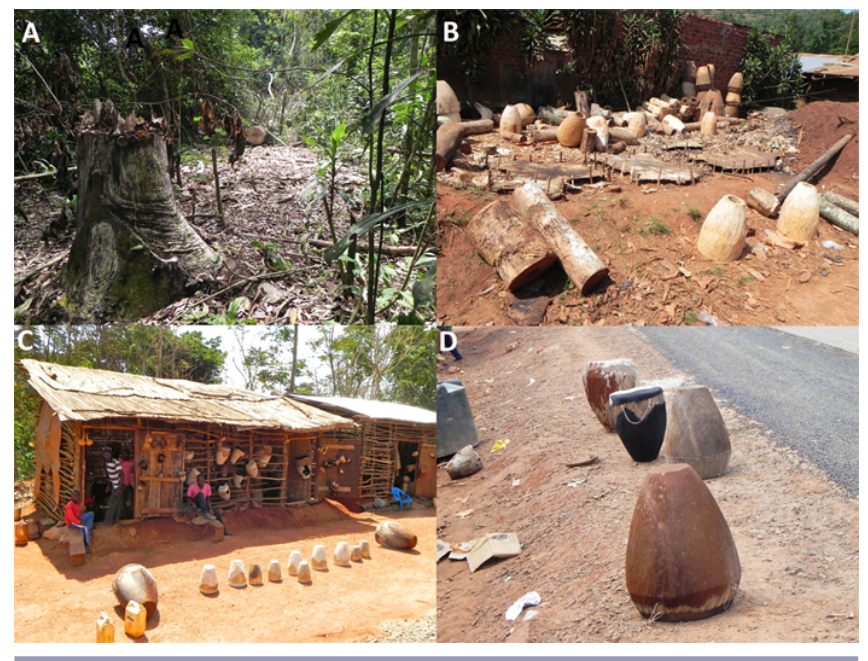

\section{Rwensama}

In Rwensama Forest, BA showed a clear decreasing trend between the two site visits (Wilcoxon test: $P=0.0012$; Fig. 3A). Expansion of agricultural plots into forest edges was so extensive that although plot locations were randomized within the 2006 extent of the forest, by 2013, four of these plots fell in areas planted with crops. Species richness showed no discernible trend $(P>0.05)$. Illegal felling was readily apparent throughout the forest. The forest survey team found numerous large stumps (Fig. 4A) in addition to very large trees in the process of being felled with simple hand tools (Fig. 4B). The team also encountered a small group of men engaged in pit sawing who ran away upon hearing the field team approach. Pit sawing is the practice of building a pit over which a felled log is propped so that it can be sawn into boards using two-person hand saws (Fig. 4C). One sawyer stands on top of the log, and another below the log. This practice is typically illegal due to the cutting of live trees, particularly large trees. In addition to this active pit sawing site, the team encountered several other sites of differing freshness.

Fig. 3. Trends in measures of forest structure and biodiversity from plot-based measurements in Rwensama Forest, Uganda. Mean (line) and 95\% confidence intervals (grey) for basal area of all trees $\geq 10 \mathrm{~cm}$ diameter at breast height (A) and tree species richness in a 50 stem sample (B). Data from both visits are from measurements of 30 circular plots each covering 0.0314 ha. The change in basal area was statistically significant (Wilcoxon test, $P=0.0012$ ), but tree diversity difference was not (simulations, $P>0.05$ ). The basal area estimate for the final survey date in Rwensama includes some farmland that had been forest during the 2006 visit but had been cleared in the intervening time. See text for additional details.
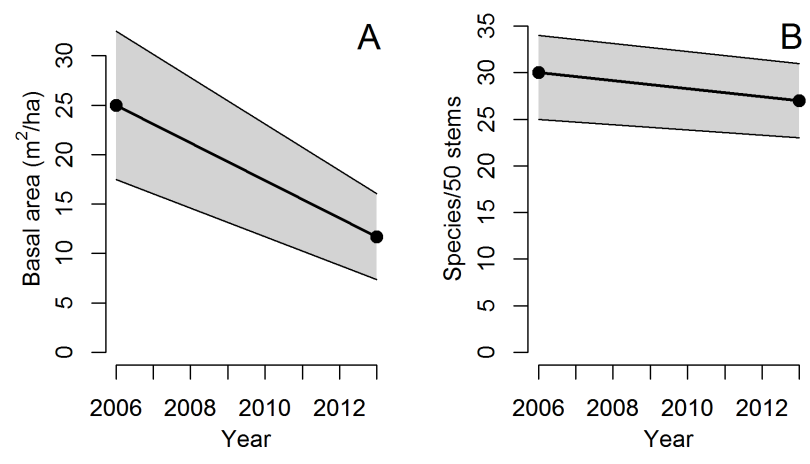

\section{DISCUSSION}

Our findings show that plot-based sampling with statistically based randomization does not provide evidence of human-driven forest degradation except in the most extreme cases, even when these changes are apparent during casual visits to the forest. In neither of our two study sites was species-specific timber extraction discernible in calculated biodiversity trends. In one site, timber cutting was detectable in BA trends, but the clearing was so extensive that 4 of 30 plots from the first survey were outside the forest seven years later. However, in spite of the difficulty of detecting these forest changes using plot-based methods, we have shown that targeted searches or even casual observations in forests can readily detect ongoing degradation. Little extra effort was needed to witness the evidence of selective tree felling in either the Mpanga or Rwensama sites (Figs. 2 and 4). Fortunately, plotbased methods are not the only way to assess forests. Below, we summarize some other possibilities and note examples of their application, both successes and failures. These methods are divided into two broad categories: direct in-forest observations, and surveys of forest users. Most of these methods, especially those targeting focal species at a particular site, would benefit from collaboration with local resource users and foresters familiar with local conditions and species. 
Fig. 4. Stages of timber harvest in Rwensama Forest, Uganda. (A) A tree in the process of being felled. The notch cut is irregular because it is made with an axe rather than a saw. (B) A cut stump. (C) A pit-sawing site. The log to be sawn into boards is propped above the ground so that a two-person crosscut saw can be used. One sawyer stands on top of the log and the other below the log.

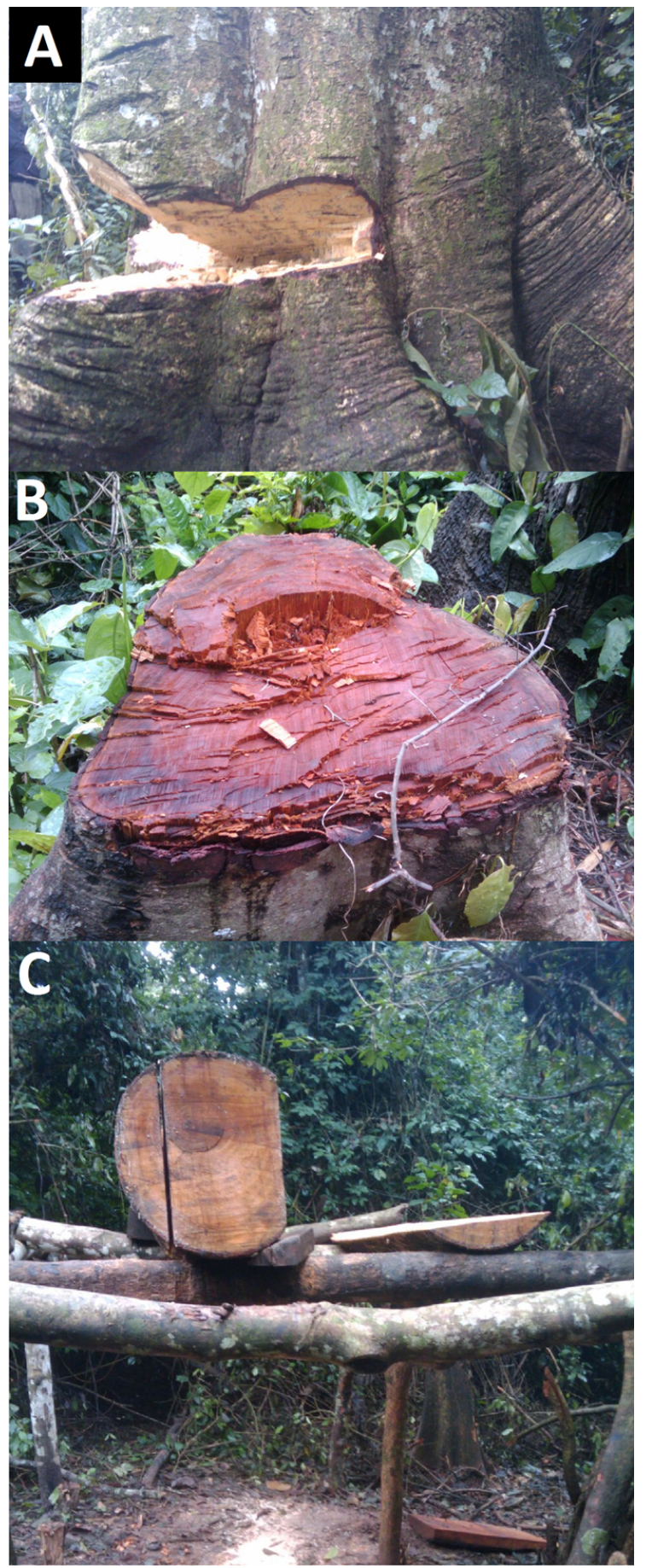

In agreement with other work on this topic (Nagendra and Ostrom 2011), we do not recommend eliminating plot-based sampling. Plot surveys involve traveling to a series of randomly selected plots within the forest, giving workers the opportunity to observe phenomena they might miss in a less directed visit. Uniform plot protocols facilitate comparisons among sites and enable detection of trends across large numbers of sites (Salk et al. 2014). Widely dispersed small plots effectively capture highly localized variability that fewer large plots can miss and are particularly effective if the same plots are censused during site revisits (Salk et al. 2013). Repeated plot-based surveys should remain a part of widely implemented long-term data collection efforts such as IFRI. To make plot-based data as useful as possible, it is helpful to report, archive, or otherwise make available the raw plot data or at least the number of stems encountered for each species. This documentation allows easier inclusion of results in meta-analyses or other comparative studies by facilitating calculation of other metrics, for instance, rarefaction computations with a different subsample size (Gotelli and Colwell 2001).

\section{Nonplot-based forest status indicators}

Here, we provide a series of nonplot forest variables that may be useful to assess biodiversity outcomes (Table 1) and present some good practices for their implementation (Table 2). These variables include direct measures of forest status and also variables that are correlates of degradation or evidence of forest-degrading activities. Collectively, we refer to these variables as forest status indicators. Although specific cost-benefit analyses are difficult to provide and depend on locally varying factors such as terrain, forest density, and the relative rarity of key species, there is little doubt that targeted surveys are more efficient than broadspectrum forest measurements. We group these variables into two categories: direct forest observations and interview-based methods.

\section{Direct forest observations}

We first focus on in-forest observations that go beyond traditional forestry plots, most of which are related to trees or other plant species. Many of these indicators are phenomena that could, in principle, be measured using plots but are too rare for plot-based sampling to capture effectively. Thus, these features may be well sampled by systematic search methods, for instance, walking predetermined transects through the forest and counting them within a fixed distance of the transect, as appropriate to local conditions and available labor. These are either positive or negative indicators, demonstrating either forest health (big, valuable, or epiphyte-laden trees, etc.) or forest degradation (stumps, hunting snares, etc.).

Disturbance-sensitive species: Some species need minimally disturbed habitats and so can be used as forest condition indicators. This idea underlies the site quality index (Swink and Wilhelm 1979), which is essentially a diversity index giving extra weight to species specific to particular habitats (Mirazadi et al. 2017). Calculating this index requires habitat preference data for all encountered species, something that could be compiled with the help of local residents or specialists. 
Table 1. A summary of the suggested potential indicators of forest state. The number of pluses or minuses indicates the authors' views on the strength of a particular advantage or disadvantage.

\begin{tabular}{|c|c|c|c|c|c|c|}
\hline \multirow[b]{2}{*}{ Indicator and brief description } & \multicolumn{3}{|c|}{ Advantage } & \multicolumn{3}{|c|}{ Drawback } \\
\hline & Easy to find & $\begin{array}{l}\text { No need to } \\
\text { identify every } \\
\text { organism }\end{array}$ & $\begin{array}{l}\text { Sensitive } \\
\text { indicator }\end{array}$ & $\begin{array}{l}\text { Variable } \\
\text { among sites }\end{array}$ & $\begin{array}{l}\text { Not present } \\
\text { everywhere }\end{array}$ & Hard to find \\
\hline $\begin{array}{l}\text { Disturbance-sensitive species: Species that are easily depleted by } \\
\text { disturbance or harvest }\end{array}$ & + & ++ & + & - & & \\
\hline $\begin{array}{l}\text { Keystone species: Species whose absence leads to big changes in } \\
\text { community and ecosystem structure }\end{array}$ & + & ++ & & - & & - \\
\hline $\begin{array}{l}\text { Big trees: Large trees are important for carbon sequestration and } \\
\text { as habitat for other species }\end{array}$ & ++ & + & + & - & - & \\
\hline $\begin{array}{l}\text { Dead wood: Standing snags and fallen logs are important habitats } \\
\text { for many species }\end{array}$ & + & & & - & & \\
\hline $\begin{array}{l}\text { Commercially valuable trees: Some species with valuable wood are } \\
\text { selectively logged }\end{array}$ & + & ++ & ++ & -- & - & \\
\hline $\begin{array}{l}\text { Slow-growing trees: Tree species that reach large stature and } \\
\text { maturity relatively slowly }\end{array}$ & + & ++ & ++ & - & & \\
\hline Epiphytes: Plants growing on other plants & + & + & + & - & - & \\
\hline $\begin{array}{l}\text { Tree regeneration: Presence and abundance of seedling and } \\
\text { saplings of large and slow-growing trees }\end{array}$ & & + & ++ & - & & - \\
\hline Stumps: Remnants of felled trees & + & + & + & - & & \\
\hline $\begin{array}{l}\text { Hunting implements:Traps, snares, or other devices to catch } \\
\text { animals }\end{array}$ & & + & + & - & - & - \\
\hline Lianas: Large woody vines & + & ++ & + & - & - & \\
\hline $\begin{array}{l}\text { Edge monitoring: Assessing forest edges for evidence of cutting, } \\
\text { conversion, fires, etc. }\end{array}$ & + & + & + & - & & \\
\hline $\begin{array}{l}\text { Key animal species: Local peoples' frequency of seeing carnivores, } \\
\text { primates, large birds, etc. }\end{array}$ & & + & + & - & & \\
\hline $\begin{array}{l}\text { Luxury species: Local peoples' frequency of encountering valuable } \\
\text { species }\end{array}$ & & + & + & - & - & \\
\hline
\end{tabular}

Table 2. Suggested practices for effective nonplot-based monitoring of forest biodiversity.

\begin{tabular}{|c|c|}
\hline Practice & Description \\
\hline $\begin{array}{l}\text { Structured } \\
\text { interviews }\end{array}$ & $\begin{array}{l}\text { Use directed questions such as "When did you last see a } \\
\text { pangolin in the forest?" or "Have you seen a pangolin in the } \\
\text { forest in the last month?" (Keane 2013) }\end{array}$ \\
\hline Replication & $\begin{array}{l}\text { Information from a sufficient number of interviews could } \\
\text { be used to statistically assess changes in forests over time or } \\
\text { differences between different forests, management regimes, } \\
\text { or governance structures }\end{array}$ \\
\hline Baseline data & $\begin{array}{l}\text { Comparisons among sites are tricky if they differ greatly in } \\
\text { climate, soils, or biogeographic history (Tucker 2008); } \\
\text { change-over-time measurements make each site its own } \\
\text { baseline, allowing easier cross-site comparisons; in the } \\
\text { absence of repeated visits or baseline data, the memory of } \\
\text { local residents can facilitate more robust comparisons }\end{array}$ \\
\hline Local involvement & $\begin{array}{l}\text { Local people can provide more than data; they can inform } \\
\text { and improve study designs and questions (Danielsen et al. } \\
\text { 2009) and collect field-based data following a training } \\
\text { period, even in remote and marginalized communities } \\
\text { (Luzar et al. 2011, Evans et al. 2018) }\end{array}$ \\
\hline Consult ecologists & $\begin{array}{l}\text { Ecologists can be useful for sampling design and to } \\
\text { understand the roles and importance of different species; } \\
\text { there is a growing appreciation among ecologists of social } \\
\text { science in conservation, and many are eager to participate } \\
\text { in this kind of study }\end{array}$ \\
\hline
\end{tabular}

Keystone species: Certain species are critical to community structure and their removal leads to big changes in other species' populations and ecosystem function (Paine 1969, Mills et al. 1993). As such, they should be an important focus of monitoring effort, although their identity is not always known or easy to determine (Power et al. 1996).
Big trees: Large old trees are particularly important for many forest processes, including as reservoirs of sequestered carbon and habitat for wildlife, epiphytes, lianas, and other species (Lindenmayer et al. 2012, Sist et al. 2014). They are a convenient indicator over extensive areas because they are easy to observe and correlate well with total aboveground biomass (Slik et al. 2013). Rare large trees are often missed by small plots, skewing BA data. However, what qualifies as "big" is context dependent. Maximum tree size depends heavily on species, climate, and soil, and forest survey protocols implemented over wide areas need to adjust size thresholds to regional factors (e.g., U.S. Department of Agriculture Forest Service 2008). Also, this attribute is unlikely to capture meaningful differences among young, regenerating forests.

Dead wood: Dead wood is of minimal timber value but high conservation value as habitat for a wide variety of animals and other organisms (Jonsson et al. 2005, Jonsell et al. 2019). Although the IFRI manual does not explicitly state whether standing dead trees should be censused, in our experience, they are not included in IFRI plot data. This is unfortunate, given their critical importance for wildlife. Also, in many places, rules or norms allow for collection only of dead wood, as in the Mpanga site. Although this restriction is meant to protect valuable live trees, such rules may negatively affect other facets of biodiversity, making monitoring of standing or fallen dead wood particularly important.

Commercially valuable trees: Some valuable tree species are logged before other species are taken (Asner et al. 2005), for example, the species used for drum making in the Mpanga site. As such, they can be seen as a leading indicator of forest degradation. The presence of valuable tree species indicates that a forest is not being 
selectively logged for short-term profit. A notorious example is the rosewoods, trees of the genus Dalbergia found in many tropical regions (Barrett et al. 2010). Some rare plant groups are sought after by collectors (orchids, cycads, palms, cacti, other succulents), leading to poaching, so they may be appropriate for this category.

Slow-growing trees: Slow-growing tree species are often of great importance to conservation (e.g., Kwit et al. 2004) and indicate that a forest has been relatively undisturbed for a long time. This category often overlaps with commercially valuable trees.

Epiphytes: A less obvious but potentially very useful indicator, especially in very wet environments, is the number of heavily epiphyte-laden trees per unit area (McCune 2000). Vascular epiphytes are sensitive indicators of climate change (Nadkarni and Solano 2002) and land-use change (Krömer and Gradstein 2003). Epiphytes are more abundant where forest tree restoration has taken place compared to naturally regenerated sites (Reid et al.2016). Epiphytes also contribute to forest structural complexity and provide habitats for a number of highly specialized animal species (Montero et al. 2010).

Tree regeneration: Surveys for seedlings or saplings of key tree species may detect failed regeneration due to lack of dispersal, seed predators, herbivores, or pathogens, and provide early warnings of invasive species. Even if trees from the valuable and slow-growing categories are well represented in the canopy, the sustainability of the population depends critically on whether the species is reproducing (Zuidema and Boot 2002). Conversely, patches of early successional species indicate disturbance.

Stumps: Recently cut stumps are a direct indicator of logging and were clearly observed in both of our study sites (Figs. 2A and 4B). They are relatively easy to find and, if not too decayed, can be identified to species from bark, wood, sprouts, or advances in molecular methods (Finkeldey et al. 2010). However, stump counts integrate over different time scales depending on how quickly wood decays, something that in turn depends on climate, decomposing organisms, and wood durability.

Hunting implements: Snares, traps, or other hunting equipment may be evidence of forest degradation. However, this indicator would not be meaningful if animal populations are so depleted that nothing remains to hunt or trap. Further, the existence of hunting does not necessarily mean that the hunting is unsustainable. Hunting disproportionately affects slowreproducing animals that have an outsized role in ecological processes such as seed dispersal (Effiom et al. 2013).

Lianas: The abundance of lianas (large woody vines) is another potential indicator of forest disturbance (Schnitzer et al. 2011). Liana abundance is known to increase with fragmentation (Laurance et al. 2001). Further, some liana species are disproportionately sensitive to climate change (Phillips et al. 2002, Mohan et al. 2006). However, very large lianas are indicative of old forests (Clark 1996).

Edge monitoring: Forest clearing frequently occurs at forest edges, as was noted at the Rwensama site. Ecological processes such as fire can cause amplifying feedbacks that may lead to further degradation of forest edges (Cochrane et al. 1999), in turn reducing carbon stocks and biodiversity. These areas should be a special target for monitoring.
Interview-based methods

Interview-based methods can complement plot-based methods and may be more cost-effective for certain species or phenomena of interest. Mortensen and Jensen (2012) found a clear costeffectiveness advantage of interview-based methods of biodiversity estimation. In fact, much information about biodiversity loss is gathered via PRA interviews under the IFRI protocol, but it is not always integrated with plot-and forest-based data. The techniques described here are more like social science methods than typical ecological fieldwork and would typically take place in an interview setting. Rather than relying on potentially time-consuming direct observations of the forest, these indicators benefit from the observations of forest users as they go about their tasks in the forest. These observations may be casual (species or phenomena observed in the course of other activities) or part of users' goals for forest visits, for instance, observations of a plant they collect or animal they hunt.

Key animal species: Some keystone animal species are important for ecological processes such as seed dispersal and regulating insect populations. Many species are also sensitive to huntinginduced population depression (Effiom et al. 2013). These groups include carnivores, frugivores (especially primates), and large birds, which can be targeted for meat, the pet trade, or because of their perceived threat to humans or livestock (Liberg et al. 2011).

Luxury species: Species that are highly desirable for local use or as trade items may be sensitive indicators of pressures on forests. This category overlaps somewhat with the previous category because primates and birds are frequently sold as food or pets. Sometimes, hunting is particularly acute when wildlife products are considered a luxury item (e.g., pangolins, bear gall bladders, rhino horn). This category is not limited to animals. Many plant species are poached for regional ornamental use or for the international collector market. When harvest is illegal, it may be difficult to get accurate information about these activities.

\section{CONCLUSION}

Our results show that plot-based survey methods do not always provide sensitive indications of forest resource depletion. We outline a variety of approaches supplementary to plot-based methods that are relatively simple to implement. Our observations demonstrate that certain indicators are readily observed with little additional effort while going about standard plot-based surveys. Such techniques should be considered by anyone interested in ecological outcomes of institutions and interventions and should be implemented whenever possible in collaboration with local communities.

Responses to this article can be read online at: http://www.ecologyandsociety.org/issues/responses. php/11223

\footnotetext{
Acknowledgments:

We thank Samuel Matovu, Sylvester Sekindi, and the other workers of the Ugandan Forestry Resources and Institutions program at Makerere University who collected the IFRI data used in this study. Funding was provided by the National Science Foundation through
} 
a Coupled Natural-Human Systems grant (DEB-1114984) and by the Belmont Forum and NORFACE Joint Research Programme on Transformations to Sustainability. M. Ara, J.-P. Benavides, M. Engman, M. Lula, O. Nilsson, L. Petersson, C. Rodriguez Gonzales, and G. A. Stecher Justiniano Pinto provided useful feedback on a draft manuscript.

\section{LITERATURE CITED}

Alexander, R. R. 2000. Modelling species extinction: the case for non-consumptive values. Ecological Economics 35(2):259-269. https://doi.org/10.1016/S0921-8009(00)00198-1

Asner, G. P., D. E. Knapp, E. N. Broadbent, P. J. C. Oliveira, M. Keller, and J. N. Silva. 2005. Selective logging in the Brazilian Amazon. Science 310(5747):480-482. https://doi.org/10.1126/ science. 1118051

Baraloto, C., B. Hérault, C. E. T. Paine, H. Massot, L. Blanc, D. Bonal, J.-F. Molino, E. A. Nicolini, and D. Sabatier. 2012. Contrasting taxonomic and functional responses of a tropical tree community to selective logging. Journal of Applied Ecology 49 (4):861-870. https://doi.org/10.1111/j.1365-2664.2012.02164.x

Barrett, M. A., J. L. Brown, M. K. Morikawa, J.-N. Labat, and A. D. Yoder. 2010. CITES designation for endangered rosewood in Madagascar. Science 328(5982):1109-1110. https://doi. org/10.1126/science. 1187740

Cardinale, B. J., C. T. Harvey, K. Gross, and A. R. Ives. 2003. Biodiversity and biocontrol: emergent impacts of a multi-enemy assemblage on pest suppression and crop yield in an agroecosystem. Ecology Letters 6(9):857-865. https://doi. org/10.1046/j.1461-0248.2003.00508.X

Carlson, K. M., G. P. Asner, R. F. Hughes, R. Ostertag, and R. E. Martin. 2007. Hyperspectral remote sensing of canopy biodiversity in Hawaiian lowland rainforests. Ecosystems 10 (4):536-549. https://doi.org/10.1007/s10021-007-9041-Z

Chapin, F. S. III, E. S. Zavaleta, V. T. Eviner, R. L. Naylor, P. M. Vitousek, H. L. Reynolds, D. U. Hooper, S. Lavorel, O. E. Sala, S. E. Hobbie, M. C. Mack, and S. Díaz. 2000. Consequences of changing biodiversity. Nature 405(6783):234-242. https://doi. org/10.1038/35012241

Clark, D. B. 1996. Abolishing virginity. Journal of Tropical Ecology 12(5):735-739. https://doi.org/10.1017/S0266467400009937

Cochrane, M. A., A. Alencar, M. D. Schulze, C. M. Souza Jr., D. C. Nepstad, P. Lefebvre, and E. A. Davidson. 1999. Positive feedbacks in the fire dynamic of closed canopy tropical forests. Science 284(5421):1832-1835. https://doi.org/10.1126/

science.284.5421.1832

Danielsen, F., N. D. Burgess, A. Balmford, P. F. Donald, M. Funder, J. P. G. Jones, P. Alviola, D. S. Balete, T. Blomley, J. Brashares, B. Child, M. Enghoff, J. Fjeldså, S. Holt, H. Hübertz, A. E. Jensen, P. M. Jensen, J. Massao, M. M. Mendoza, Y. Ngaga, M. K. Poulsen, R. Rueda, M. Sam, T. Skielboe, G. Stuart-Hill, E. Topp-Jørgensen, and D. Yonten. 2009. Local participation in natural resource monitoring: a characterization of approaches. Conservation Biology 23(1):31-42. https://doi.org/10.1111/ j.1523-1739.2008.01063.x
Díaz, S., J. Fargione, F. S. Chapin III, and D. Tilman. 2006. Biodiversity loss threatens human well-being. Plos Biology 4(8): e277. https://doi.org/10.1371/journal.pbio.0040277

Dornelas, M., A. E. Magurran, S. T. Buckland, A. Chao, R. L. Chazdon, R. K. Colwell, T. Curtis, K. J. Gaston, N. J. Gotelli, M. A. Kosnik, B. McGill, J. L. McCune, H. Morlon, P. J. Mumby, L. Øvreås, A. Studeny, and M. Vellend. 2013. Quantifying temporal change in biodiversity: challenges and opportunities. Proceedings of the Royal Society B 280(1750):20121931. https://doi. org/10.1098/rspb.2012.1931

Effiom, E. O., G. Nuñez-Iturri, H. G. Smith, U. Ottosson, and O. Olsson. 2013. Bushmeat hunting changes regeneration of African rainforests. Proceedings of the Royal Society $B \quad 280$ (1759):20130246. https://doi.org/10.1098/rspb.2013.0246

Evans, K., M. R. Guariguata, and P. H. S. Brancalion. 2018. Participatory monitoring to connect local and global priorities for forest restoration. Conservation Biology 32(3):525-534. https:// doi.org/10.1111/cobi.13110

Ferrier, S., and M. Drielsma. 2010. Synthesis of pattern and process in biodiversity conservation assessment: a flexible wholelandscape modelling framework. Diversity and Distributions 16 (3):386-402. https://doi.org/10.1111/j.1472-4642.2010.00657.x

Finkeldey, R., L. Leinemann, and O. Gailing. 2010. Molecular genetic tools to infer the origin of forest plants and wood. Applied Microbiology and Biotechnology 85(5):1251-1258. https://doi. org/10.1007/s00253-009-2328-6

Fornoff, F., A.-M. Klein, N. Blüthgen, and M. Staab. 2019. Tree diversity increases robustness of multi-trophic interactions. Proceedings of the Royal Society B 286(1898):20182399. https:// doi.org/10.1098/rspb.2018.2399

Gotelli, N. J., and R. K. Colwell. 2001. Quantifying biodiversity: procedures and pitfalls in the measurement and comparison of species richness. Ecology Letters 4(4):379-391. https://doi. org/10.1046/j.1461-0248.2001.00230.x

Hansen, M. C., P. V. Potapov, R. Moore, M. Hancher, S. A. Turubanova, A. Tyukavina, D. Thau, S. V. Stehman, S. J. Goetz, T. R. Loveland, A. Kommareddy, A. Egorov, L. Chini, C. O. Justice, and J. R. G. Townshend. 2013. High-resolution global maps of 21st-century forest cover change. Science 342 (6160):850-853. http://dx.doi.org/10.1126/science.1244693

Harvey, C. A., B. Dickson, and C. Kormos. 2010. Opportunities for achieving biodiversity conservation through REDD. Conservation Letters 3(1):53-61. https://doi.org/10.1111/ j.1755-263X.2009.00086.X

Jones, D. T., and P. Eggleton. 2000. Sampling termite assemblages in tropical forests: testing a rapid biodiversity assessment protocol. Journal of Applied Ecology 37(1):191-203. https://doi. org/10.1046/j.1365-2664.2000.00464.X

Jonsell, M., M. Abrahamsson, L. Widenfalk, and M. Lindbladh. 2019. Increasing influence of the surrounding landscape on saproxylic beetle communities over 10 years succession in dead wood. Forest Ecology and Management 440:267-284. https://doi. org/10.1016/j.foreco.2019.02.021 
Jonsson, B. G., N. Kruys, and T. Ranius. 2005. Ecology of species living on dead wood - lessons for dead wood management. Silva Fennica 39(2):390. https://doi.org/10.14214/sf.390

Justus, J. 2011. A case study in concept determination: ecological diversity. Pages 147-168 in K. deLaplante, B. Brown, and K. A. Peacock, editors. Philosophy of ecology. Elsevier, Oxford, UK. https://doi.org/10.1016/B978-0-444-51673-2.50006-6

Justus, J., M. Colyvan, H. Regan, and L. Maguire. 2009. Buying into conservation: intrinsic versus instrumental value. Trends in Ecology and Evolution 24(4):187-191. https://doi.org/10.1016/j. tree.2008.11.011

Keane, A. 2013. Unusual data in conservation science: searching for validation. Animal Conservation 16(6):604-605. https://doi. org/10.1111/acv.12091

Krömer, T., and S. R. Gradstein. 2003. Species richness of vascular epiphytes in two primary forests and fallows in the Bolivian Andes. Selbyana 24(2):190-195. [online] URL: https:// www.jstor.org/stable/41760132

Kwit, C., C. C. Horvitz, and W. J. Platt. 2004. Conserving slowgrowing, long-lived tree species: input from the demography of a rare understory conifer, Taxus floridana. Conservation Biology 18 (2):432-443. https://doi.org/10.1111/j.1523-1739.2004.00567.x

Laurance, W. F., D. Pérez-Salicrup, P. Delamônica, P. M. Fearnside, S. D’Angelo, A. Jerozolinski, L. Pohl, and T. E. Lovejoy. 2001. Rain forest fragmentation and the structure of Amazonian liana communities. Ecology 82(1):105-116. https:// doi.org/10.1890/0012-9658(2001)082[0105:RFFATS]2.0.CO;2

Liang, J., T. W. Crowther, N. Picard, S. Wiser, M. Zhou, G. Alberti, E.-D. Schulze, A. D. McGuire, F. Bozzato9, H. Pretzsch, S. deMiguel, A. Paquette, B. Hérault, M. Scherer-Lorenzen, C. B. Barrett, H. B. Glick, G. M. Hengeveld, G.-J. Nabuurs, S. Pfautsch, H. Viana, A. C. Vibrans, C. Ammer, P. Schall, D. Verbyla, N. Tchebakova, M. Fischer, J. V. Watson, H. Y. H. Chen, X. Lei, M.J. Schelhaas, H. Lu, D. Gianelle, E. I. Parfenova, C. Salas, E. Lee, B. Lee, H. S. Kim, H. Bruelheide, D. A. Coomes, D. Piotto, T. Sunderland, B. Schmid, S. Gourlet-Fleury, B. Sonké, R. Tavani, J. Zhu, S. Brandl, J. Vayreda, F. Kitahara, E. B. Searle, V. J. Neldner, M. R. Ngugi, C. Baraloto, L. Frizzera, R. Balazy, J. Oleksyn, T. Zawila-Niedzwiecki, O. Bouriaud, F. Bussotti, L. Finér, B. Jaroszewicz, T. Jucker, F. Valladares, A. M. Jagodzinski, P. L. Peri, C. Gonmadje, W. Marthy, T. O'Brien, E. H. Martin, A. R. Marshall, F. Rovero, R. Bitariho, P. A. Niklaus, P. AlvarezLoayza, N. Chamuya, R. Valencia, F. Mortier, V. Wortel, N. L. Engone-Obiang, L. V. Ferreira, D. E. Odeke, R. M. Vasquez, S. L. Lewis, P. B. Reich. 2016. Positive biodiversity-productivity relationship predominant in global forests. Science 354(6309): aa18957. https://doi.org/10.1126/science.aaf8957

Liberg, O., G. Chapron, P. Wabakken, H. C. Pedersen, N. T. Hobbs, and H. Sand. 2011. Shoot, shovel and shut up: cryptic poaching slows restoration of a large carnivore in Europe. Proceedings of the Royal Society B 279(1730):910-915. https://doi. org/10.1098/rspb.2011.1275

Lindenmayer, D. B., W. F. Laurance, and J. F. Franklin. 2012. Global decline in large old trees. Science 338(6112):1305-1306. https://doi.org/10.1126/science. 1231070
Luzar, J. B., K. M. Silvius, H. Overman, S. T. Giery, J. M. Read, and J. M. V. Fragoso. 2011. Large-scale environmental monitoring by indigenous peoples. Bioscience 61(10):771-781. https://doi. org/10.1525/bio.2011.61.10.7

Mace, G. M., K. Norris, and A. H. Fitter. 2012. Biodiversity and ecosystem services: a multilayered relationship. Trends in Ecology and Evolution 27(1):19-26. https://doi.org/10.1016/j.tree.2011.08.006

McCune, B. 2000. Lichen communities as indicators of forest health. Bryologist 103(2):353-356. https://doi.org/10.1639/0007-2745 (2000)103[0353:LCAIOF]2.0.CO:2

Millennium Ecosystem Assessment. 2005. Ecosystems and human well-being: synthesis. Island Press, Washington, D.C., USA. [online] URL: https://www.millenniumassessment.org/documents/ document.356.aspx.pdf

Mills, L. S., M. E. Soulé, and D. F. Doak. 1993. The keystonespecies concept in ecology and conservation: management and policy must explicitly consider the complexity of interactions in natural systems. Bioscience 43(4):219-224. https://doi. org/10.2307/1312122

Mirazadi, Z., B. Pilehvar, and K. A. Vajari. 2017. Diversity indices or floristic quality index: Which one is more appropriate for comparison of forest integrity in different land uses? Biodiversity and Conservation 26(5):1087-1101. https://doi.org/10.1007/ s10531-016-1287-3

Mohan, J. E., L. H. Ziska, W. H. Schlesinger, R. B. Thomas, R. C. Sicher, K. George, and J. S. Clark. 2006. Biomass and toxicity responses of poison ivy (Toxicodendron radicans) to elevated atmospheric $\mathrm{CO}_{2}$. Proceedings of the National Academy of Sciences 103(24):9086-9089. https://doi.org/10.1073/pnas.0602392103

Montero, G., C. Feruglio, and I. M. Barberis. 2010. The phytotelmata and foliage macrofauna assemblages of a bromeliad species in different habitats and seasons. Insect Conservation and Diversity 3(2):92-102. https://doi.org/10.1111/j.1752-4598.2009.00077. $\underline{\mathrm{X}}$

Mortensen, L. O., and M. B. Jensen. 2012. Methods in sustainable monitoring: plot sampling versus interviews. Biodiversity and Conservation 21(1):145-153. https://doi.org/10.1007/s10531-011-0171-4

Nadkarni, N. M., and R. Solano. 2002. Potential effects of climate change on canopy communities in a tropical cloud forest: an experimental approach. Oecologia 131(4):580-586. https://doi. org/10.1007/s00442-002-0899-3

Naeem, S., R. Chazdon, J. E. Duffy, C. Prager, and B. Worm. 2016. Biodiversity and human well-being: an essential link for sustainable development. Proceedings of the Royal Society B 283 (1844):20162091. https://doi.org/10.1098/rspb.2016.2091

Nagendra, H., and E. Ostrom. 2011. The challenge of forest diagnostics. Ecology and Society 16(2):20. https://doi. org/10.5751/ES-04189-160220

Naughton-Treves, L., D. M. Kammen, and C. Chapman. 2007. Burning biodiversity: woody biomass use by commercial and subsistence groups in western Uganda's forests. Biological Conservation 134(2):232-241. https://doi.org/10.1016/j.biocon.2006.08.020 
Paine, R.T. 1969. A note on trophic complexity and community stability. American Naturalist 103(929):91-93. https://doi. org/10.1086/282586

Pearson, R. G., J. C. Stanton, K. T. Shoemaker, M. E. AielloLammens, P. J. Ersts, N. Horning, D. A. Fordham, C. J. Raxworthy, H. Y. Ryu, J. McNees, and H. R. Akçakaya. 2014. Life history and spatial traits predict extinction risk due to climate change. Nature Climate Change 4(3):217-221. https://doi. org/10.1038/nclimate2113

Persha, L., A. Agrawal, and A. Chhatre. 2011. Social and ecological synergy: local rulemaking, forest livelihoods, and biodiversity conservation. Science 331(6024):1606-1608. https:// doi.org/10.1126/science.1199343

Pettorelli, N., W. F. Laurance, T. G. O’Brien, M. Wegmann, H. Nagendra, and W. Turner. 2014. Satellite remote sensing for applied ecologists: opportunities and challenges. Journal of Applied Ecology 51(4):839-848. https://doi.org/10.1111/1365-2664.12261

Phillips, O. L., R. V. Martínez, L. Arroyo, , T. R. Baker, T. Killeen, S. L. Lewis, Y. Malhi, A. M. Mendoza, D. Neill, P. N. Vargas, M. Alexiades, C. Cerón, A. Di Fiore, T. Erwin, A. Jardim, W. Palacios, M. Saldias, and B. Vinceti. 2002. Increasing dominance of large lianas in Amazonian forests. Nature 418(6899):770-774. https:// doi.org/10.1038/nature00926

Piccolo, J. J., H. Washington, H. Kopnina, and B. Taylor. 2018. Why conservation scientists should re-embrace their ecocentric roots. Conservation Biology 32(4):959-961. https://doi.org/10.1111/ cobi.13067

Power, M. E., D. Tilman, J. A. Estes, B. A. Menge, W. J. Bond, L. S. Mills, G. Daily, J. C. Castilla, J. Lubchenco, and R. T. Paine. 1996. Challenges in the quest for keystones: identifying keystone species is difficult - but essential to understanding how loss of species will affect ecosystems. Bioscience 46(8):609-620. https:// doi.org/10.2307/1312990

R Core Team. 2014. R: a language and environment for statistical computing. R Foundation for Statistical Computing, Vienna, Austria.

Reid, J. L., J. M. Chaves-Fallas, K. D. Holl, and R. A. Zahawi. 2016. Tropical forest restoration enriches vascular epiphyte recovery. Applied Vegetation Science 19(3):508-517. https://doi. org/10.1111/avsc. 12234

Ribeiro, M. C., J. P. Metzger, A. C. Martensen, F. J. Ponzoni, and M. M. Hirota. 2009. The Brazilian Atlantic forest: How much is left, and how is the remaining forest distributed? Implications for conservation. Biological Conservation 142(6):1141-1153. https:// doi.org/10.1016/j.biocon.2009.02.021

Salk, C. F., R. L. Chazdon, and K. P. Andersson. 2013. Detecting landscape-level changes in tree biomass and biodiversity: methodological constraints and challenges of plot-based approaches. Canadian Journal of Forest Research 43(9):799-808. https://doi.org/10.1139/cjfr-2013-0048

Salk, C. F., U. Frey, and H. Rusch. 2014. Comparing forests across climates and biomes: qualitative assessments, reference forests and regional intercomparisons. Plos One 9(4):e94800. https://doi. org/10.1371/journal.pone.0094800
Schnitzer, S. A., F. Bongers, and S. J. Wright. 2011. Community and ecosystem ramifications of increasing lianas in neotropical forests. Plant Signaling and Behavior 6(4):598-600. https://doi. org/10.4161/psb.6.4.15373

Sist, P., L. Mazzei, L. Blanc, and E. Rutishauser. 2014. Large trees as key elements of carbon storage and dynamics after selective logging in the eastern Amazon. Forest Ecology and Management 318:103-109. https://doi.org/10.1016/j.foreco.2014.01.005

Slik, J. W. F., G. Paoli, K. McGuire, I. Amaral, J. Barroso, M. Bastian, L. Blanc, F. Bongers, P. Boundja, C. Clark, M. Collins, G. Dauby, Y. Ding, J.-L. Doucet, E. Eler, L. Ferreira, O. Forshed, G. Fredriksson, J.-F. Gillet, D. Harris, M. Leal, Y. Laumonier, Y. Malhi, A. Mansor, E. Martin, K. Miyamoto, A. AraujoMurakami, H. Nagamasu, R. Nilus, E. Nurtjahya, Á. Oliveira, O. Onrizal, A. Parada-Gutierrez, A. Permana, L. Poorter, J. Poulsen, H. Ramirez-Angulo, J. Reitsma, F. Rovero, A. Rozak, D. Sheil, J. Silva-Espejo, M. Silveira, W. Spironelo, H. ter Steege, T. Stevart, G. E. Navarro-Aguilar, T. Sunderland, E. Suzuki, J. Tang, I. Theilade, G. van der Heijden, J. van Valkenburg, T. V. Do, E. Vilanova, V. Vos, S. Wich, H. Wöll, T. Yoneda, R. Zang, M.-G. Zhang, N. Zweifel. 2013. Large trees drive forest aboveground biomass variation in moist lowland forests across the tropics. Global Ecology and Biogeography 22(12):1261-1271. https://doi.org/10.1111/geb.12092

Swink, F., and G. Wilhelm. 1979. Plants of the Chicago region. Morton Arboretum, Lisle, Illinois, USA.

Terborgh, J., G. Nuñez-Iturri, N. C. A. Pitman, F. H. C. Valverde, P. Alvarez, V. Swamy, E. G. Pringle, and C. E. T. Paine. 2008. Tree recruitment in an empty forest. Ecology 89(6):1757-1768. https:// doi.org/10.1890/07-0479.1

Tucker, C. M., J. C. Randolph, T. Evans, K. P. Andersson, L. Persha, and G. M. Green. 2008. An approach to assess relative degradation in dissimilar forests: toward a comparative assessment of institutional outcomes. Ecology and Society 13 (1):4. https://doi.org/10.5751/ES-02262-130104

U.S. Agency for International Development (USAID). 2015. USAID's biodiversity conservation and forestry programs, 2015 report: FY 2014 results and funding. U.S. Agency for International Development, Washington, D.C., USA. [online] URL: http://pdf. usaid.gov/pdf docs/PA00KT5S.pdf

U.S. Department of Agriculture Forest Service. 2008. Field instructions for the annual inventory of California, Oregon and Washington. U.S. Department of Agriculture Forest Service Pacific Northwest Research Station, Corvallis, Oregon, USA. [online] URL: https://www.fs.fed.us/pnw/rma/fia-topics/documentation/ field-manuals/documents/Annual/2008_annual_inventory_pnw_south. pdf

Wertime, M. B., E. Ostrom, C. C. Gibson, and F. Lehoucq. 2008. International Forestry Resources and Institutions research program fieldmanual. Center for the Study of Institutions, Population, and Environmental Change, Indiana University, Bloomington, Indiana, USA. [online] URL: http://ifri.forgov.org/wp-content/ uploads/2012/09/IFRI Manual.pdf

Wright, S. J., A. Hernandéz, and R. Condit. 2007. The bushmeat harvest alters seedling banks by favoring lianas, large seeds, and 
seeds dispersed by bats, birds, and wind. Biotropica 39(3):363-371. https://doi.org/10.1111/j.1744-7429.2007.00289.x

Zuidema, P. A., and R. G. A. Boot. 2002. Demography of the Brazil nut tree (Bertholletia excelsa) in the Bolivian Amazon: impact of seed extraction on recruitment and population dynamics. Journal of Tropical Ecology 18(1):1-31. https://doi. org/10.1017/S0266467402002018 